\title{
Simultaneous surgical treatment of liver metastases from colorectal cancer in the elderly through Habib's technique
}

\author{
Xheseda Dumani, Gennaro Rizzo, Sebastiano Grassia, Vincenzo Tammaro, Nicola Carlomagno, Andrea Renda \\ From 26th National Congress of the Italian Society of Geriatric Surgery \\ Naples, Italy. 19-22 June 2013
}

\begin{abstract}
Introduction
The liver is the most common site of metastasis from colo-rectal cancer (CRC) that may already be present up to $30 \%$ of cases the diagnosis of the primary tumor. In recent years, thanks to the improvement of surgical techniques and chemotherapy, the prognosis is improved and the criteria for a correct indication for surgery are less restrictive than in the past. The behaviour in the presence of synchronous liver metastases (ME), however, is still controversial, and removal of the primary tumor and $\mathrm{ME}$ can occur at different times. In view of the improvement of surgical techniques and perioperative management of technological development, in some selected cases a contemporary approach can be planned. We have thus decided to conduct a retrospective study to evaluate whether there is increased risk of morbidity 'and mortality, as well as a significant increase in operative time, especially focusing on the influence of age in the simultaneous treatment of the primary tumor and ME.
\end{abstract}

\section{Methods}

From 2004 to 2012, we treated 36 patients (23 males and 13 females) affected by CRC with liver metastases at diagnosis. We divided the patients into two groups:

Group A (21 patients) aged less than 70 y.o. (range 48-70) - M: F = 1:2

Group B (15 patients) $>70$ years y.o. (range $71-84$ years) - $M: F=1: 3$

Simultaneous treatment was based on the following inclusion criteria: patient's general health status, ASA score, characteristics of liver metastases (site, size and number) and percentage of healthy liver. Pre-operative

\footnotetext{
* Correspondence: dumani1985@libero.it
U.O.C. Chirurgia Generale ad Indirizzo Addominale, Università Federico II -

* Correspondence: dumani1985@libero.it
U.O.C. Chirurgia Generale ad Indirizzo Addominale, Università Federico II via Pansini 5 Napoli, Italy
}

C 2013 Dumani et al; licensee BioMed Central Ltd. This is an Open Access article distributed under the terms of the Creative Commons Attribution License (http://creativecommons.org/licenses/by/2.0), which permits unrestricted use, distribution, and reproduction in any medium, provided the original work is properly cited.

\section{Results}

We performed 51 metastasectomies (in 33 patients) and 3 wedge resections. We never used Pringle's manoeuvre. Mean intraoperative blood loss was $150 \mathrm{ml}$ (range 100-350 cc) and only one patient required a blood transfusion. The mean increase of operation time was 35 minutes. Postoperative outcome was acceptable in all cases. Bowel motility started at 48-72 h. Mean drainage output was $180 \mathrm{cc}$ at $24 \mathrm{~h}$ and $70 \mathrm{cc}$ at 48h. Modest and transient increase in liver function tests verified in almost all cases. There were no major systemic complications, just one patient postoperatively suffered hepato-renal failure treated in intensive care unit. Patients were discharged on the 9th-12th day. There was no mortality. Results according to the different ages are reported in table 1.

\section{Conclusions}

Habib's device allowed us to perform metastasecomies at the same time of colectomy without Pringle's manoeuvre, with minimal blood loss and without excessive 
Table 1 Results according to the different ages

\begin{tabular}{lccccc}
\hline & Intra-operative blood loss (cc) & Increase of operative time (minutes) & Morbidity (n) & Mortality (n) & Mean hospitalization time (days) \\
\hline Group A & $120 \mathrm{ml}$ (range 80-320 cc) & 35 & $2(9,5 \%)$ & - & 11 \\
\hline Group B & $160 \mathrm{ml}$ (range 100-350 cc) & 35 & $3(20 \%)$ & - & 12 \\
\hline
\end{tabular}

prolongation of the surgical time. In both groups postoperative haemorrhage and biliary leak were minimal, supporting the effectiveness of the technique. Our experience showed that Habib's procedure is easy and safe. It is our opinion that such device allows liver resections to be carried out with minimal blood loss and low mortality and morbidity rates, and results are similar between young and old patients.

Published: 16 September 2013

\section{References}

1. Weber Jean-Christophe, Navarra Giuseppe, Jiao Long R, Nicholls Joanna P, Jensen Steen Lindkaer, Habib Nagy A: New Technique for Liver Resection Using Heat Coagulative Necrosis. Annals of Surgery 2002, 236(5):560-563.

2. Weber JC, Navarra G, Habib NA, Bachellier P, Jaeck D: Laparoscopic radiofrequency-assisted liver resection. Surg Endosc 2003, 17:831-834.

3. Rispoli C, Rocco N, lannone L, Amato B: Developing guidelines in geriatric surgery: role of the grade system. BMC Geriatrics 2009, 9(SUPPL.1):A99.

4. Ayav Ahmet, Navarra Giuseppe, Habib Nagy A, Jiao Long R: New Technique for Liver Resection Using Heat Coagulative Necrosis. Annals of Surgery 2005, 242(5)

5. Stavrou GA, Tzias Z, von Falck C, Habib N, Oldhafer KJ: Hepatic resection using heat coagulative necrosis. First report of successful trisegmentectomy after hypertrophy induction. Langenbecks Arch Surg 2007, 392(1):95-97.

6. Mastromarino R, D'Angelo S, Saglioccolo A, Rizzo G, Tammaro V, Carlomagno N, Renda A: Preliminary results with habib's procedure. BMC Geriatrics 2011, 11(Suppl 1):A32.

doi:10.1186/1471-2482-13-S1-A49

Cite this article as: Dumani et al:: Simultaneous surgical treatment of liver metastases from colorectal cancer in the elderly through Habib's technique. BMC Surgery 2013 13(Suppl 1):A49.

\section{Submit your next manuscript to BioMed Central} and take full advantage of:

- Convenient online submission

- Thorough peer review

- No space constraints or color figure charges

- Immediate publication on acceptance

- Inclusion in PubMed, CAS, Scopus and Google Scholar

- Research which is freely available for redistribution

Submit your manuscript at www.biomedcentral.com/submit 